\title{
Fifteen years in a global warming hotspot: changes in subtidal mobile invertebrate communities
}

\author{
Y. R. Mulders ${ }^{1,2, *}$, T. Wernberg ${ }^{1,2,3}$ \\ ${ }^{1}$ UWA Oceans Institute, The University of Western Australia, 35 Stirling Hwy, Crawley, WA 6009, Australia \\ ${ }^{2}$ School of Biological Sciences, The University of Western Australia, 35 Stirling Hwy, Crawley, WA 6009, Australia \\ ${ }^{3}$ Department of Science and Environment, Roskilde University, 4000 Roskilde, Denmark
}

\begin{abstract}
Temperate subtidal reefs are increasingly exposed to gradual warming and short periods of high temperatures (marine heatwaves; MHWs). These pressures can directly and indirectly affect the mobile invertebrate communities on these reefs. We investigate changes in mobile invertebrate communities from benthic surveys $15 \mathrm{yr}$ apart (1999-2001 vs 2016-2019), spanning a $4^{\circ}$ latitudinal gradient in Western Australia $\left(30-34^{\circ} \mathrm{S}\right)$, expecting the biggest changes to the communities in the lower latitudes, where the cumulative effect of MHWs and warming is largest. The urchins Centrostephanus tenuispinus (warm temperate affinity) and Phyllacanthus irregularis (cool temperate affinity) showed trends toward opposite responses over time; while $P$. irregularis densities declined (non-significantly at all sites), C. tenuispinus densities increased (significantly at one of 3 sites). The magnitude of the responses appeared to decrease with increasing latitude, with C. tenuispinus recorded in significantly higher densities only at the lowest latitude location. Neither the densities, nor change in density over time of cool temperate gastropod Lunella torquatus and urchin Heliocidaris erythrogramma reflected a latitudinal gradient, suggesting other localized factors play a larger role in determining abundances of these species. However, size distributions of L. torquatus populations at the lower latitude locations were clearly impacted by the $2011 \mathrm{MHW}$, while those at higher latitudes remained relatively consistent. Overall, the biggest changes over time were seen at the warm edge of the temperate ecosystem. As temperatures continue to rise, the magnitude of these changes is not only expected to increase, but also to occur at higher latitudes.
\end{abstract}

KEY WORDS: Gradual warming - Marine heatwaves - Temperate reefs $\cdot$ Temperate rocky reef assemblages $\cdot$ Southwest Australia

\section{INTRODUCTION}

Ocean temperatures have been gradually increasing globally for decades, and are projected to continue to rise in the foreseeable future (IPCC 2018). In addition to this gradual warming, there has been an increase in the frequency and intensity of short but severe marine heatwaves (MHWs) (Oliver et al. 2018, 2019). Temperature is one of the most pervasive factors in determining marine species distributions (Perry et al. 2005, Poloczanska et al. 2013, Wernberg et al. 2013b). As such, increasing temperatures and acute heat events have affected flora and fauna

${ }^{*}$ Corresponding author:

yannick.mulders@research.uwa.edu.au worldwide, resulting in changing abundances (Schiel et al. 2004, Poloczanska et al. 2016, Bowler et al. 2017), changes in population structure (Sheridan \& Bickford 2011), range shifts (Johnson et al. 2011, Smale \& Wernberg 2013, Wernberg et al. 2016a), or local extinctions (Wernberg et al. 2016a, Straub et al. 2019, Thomsen et al. 2019).

Over the past decades, the marine environment in Western Australia (WA) has experienced a gradual increase in sea temperature (Pearce \& Feng 2007), as well as the frequency and intensity of MHWs (Pearce et al. 2011a, Pearce \& Feng 2013, Hobday et al. 2016). In the Australasian summer of 2010-2011, one of the restricted. Authors and original publication must be credited. 
most extreme MHWs recorded globally occurred in WA (Pearce \& Feng 2013, Wernberg et al. 2013a, Wernberg 2020), and was followed by 2 summers of anomalously high temperatures (Caputi et al. 2015). When considering both gradual warming and MHWs, Western Australian reefs are among the fastest warming locations in the world (Hobday \& Pecl 2014). These reefs are at the western edge of the Great Southern Reef (GSR); a collective of temperate subtidal reefs stretching along the southern coast of Australia to Kalbarri in the northwest (Bennett et al. 2016). Here, dense stands of large canopy-forming macroalgae dominate the benthos (Coleman \& Wernberg 2017, Wernberg et al. 2019). In temperate WA, Ecklonia radiata is the dominant macroalga, and supports a productive (De Bettignies et al. 2013), diverse (Kerswell 2006), and economically valuable ecosystem (Bennett et al. 2016).

The increasing temperature stress has had a profound effect on the canopy-forming macroalgae, and the 2011 MHW by itself resulted in the loss of an estimated $963 \mathrm{~km}^{2}$ of kelp forest along the WA coast (Wernberg et al. 2016a). At the lower latitudes, where the MHW was most intense, 2 conspicuous canopyforming species, E. radiata and Scytothalia dorycarpa, became functionally extinct, reducing the northern limit of their range by around $100 \mathrm{~km}$ (Smale \& Wernberg 2013, Wernberg et al. 2016a). The resulting competitive release of space provided the opportunity for different species of benthic primary producers to exploit this resource. The loss of canopy was followed by an increase in abundance and cover of turf algae (Wernberg et al. 2013a, 2016a, Bennett et al. 2015, Filbee-Dexter \& Wernberg 2018), and subsequently corals (Tuckett et al. 2017).

As these canopy-forming macroalgae are foundation species in the temperate subtidal ecosystem, their reduction resulted in changes to associated mobile invertebrate communities (Smale et al. 2017). The most dramatic changes were seen at the northern edge of the temperate bioregion, where the canopy-forming macroalgae went functionally extinct. Here, no mobile invertebrates were encountered directly after the MHW. Furthermore, urchins with warm- to tropical affinities increased in abundance, while urchins and gastropods with temperate affinities decreased (Smale et al. 2017). The magnitude of the changes seen in the invertebrate communities was relative to the severity of the impact of the MHW, highest in the lower latitudes to negligible in the higher latitudes.

While the changes to foundation species will often affect the associated invertebrate community, it can also work the other way around. In kelp forests worldwide, urchins can cause the collapse of the dominant kelp (Steneck et al. 2002, Ling 2008, Ling et al. 2015), or maintain a barren benthic state after the kelp has disappeared (Filbee-Dexter \& Scheibling 2014). No large-scale urchin barrens have been reported in WA. However, on the east coast of Australia and Tasmania, where warming currents are bringing urchin larvae southwards (Johnson et al. 2005, Ling et al. 2008), and predators such as rock lobster have been overfished (Ling \& Johnson 2012), Centrostephanus rodgersii (long-spined sea urchin) abundance has increased, which led to the overgrazing of macroalgae (Andrew \& Underwood 1993, Andrew \& O'Neill 2000, Johnson et al. 2005).

This research builds on the available historical data on the distributions and abundance of mobile invertebrates (Vanderklift \& Kendrick 2004, Wernberg et al. 2008) along the WA temperate coast, and the response of the mobile invertebrate community to the 2011 MHW (Smale et al. 2017). We investigate the ongoing response of mobile invertebrate communities subjected to both gradual ocean warming and MHWs by comparing the abundance and diversity of all mobile invertebrates, as well as the size distribution of the most abundant and conspicuous gastropod (Lunella torquatus) populations, over a decadal timespan and a latitudinal gradient. This gradient spans reefs severely impacted by the MHW at the lower latitudes, to reefs only mildly affected at the higher latitudes, while all locations along the gradient have been exposed to gradual warming. We hypothesize that the gradual warming and extreme heat event work synergistically, and as such we expect to find the biggest changes to the mobile invertebrate communities over time at the lower latitudes, where the cumulative effects have been largest.

\section{MATERIALS AND METHODS}

\subsection{Study location}

This study focussed on 3 locations in south-western WA: Jurien Bay, Marmion Lagoon (hereafter referred to as 'Marmion'), and Hamelin Bay, which are separated by roughly $2^{\circ}$ of latitude while having similar longitudes (Table 1, Fig. 1). Due to this north to south orientation, ocean temperatures reflect the latitudinal gradient, generally being $1-2^{\circ} \mathrm{C}$ warmer in the lower latitudes and cooler in the higher latitudes (Table 1, Fig. 1). Similarly, the 2011 MHW also had the biggest impact at low latitudes and decreasing impact with increasing latitude (Table 1) (Wernberg et al. 2018). 
Table 1. Coordinates for the surveyed locations, mean annual sea surface temperature (SST) between 1993 and 2019 , the gradual SST increase at each location based on mean summer SST (see also Fig. 2A), and the peak SST during the marine heat wave (MHW)

\begin{tabular}{|lccccc|}
\hline Location & $\begin{array}{c}\text { Latitude } \\
\left({ }^{\circ} \mathrm{S}\right)\end{array}$ & $\begin{array}{c}\text { Longitude } \\
\left({ }^{\circ} \mathrm{E}\right)\end{array}$ & $\begin{array}{c}\text { Mean annual SST } \\
\left({ }^{\circ} \mathrm{C}\right)\end{array}$ & $\begin{array}{c}\text { SST increase } \\
\left({ }^{\circ} \mathrm{C} \mathrm{yr}^{-1}\right)\end{array}$ & $\begin{array}{c}\text { Peak MHW SST } \\
\left({ }^{\circ} \mathrm{C}\right)\end{array}$ \\
\hline Jurien Bay & 30.266 & 114.975 & 21.01 & 0.0192 & 27.97 \\
Marmion & 31.852 & 115.713 & 20.17 & 0.0201 & 26.37 \\
Hamelin Bay & 34.218 & 115.010 & 19.69 & $\left(\mathrm{r}^{2}=0.0364, \mathrm{p}=0.34\right)$ & $0.0703, \mathrm{p}=0.18)$ \\
\end{tabular}

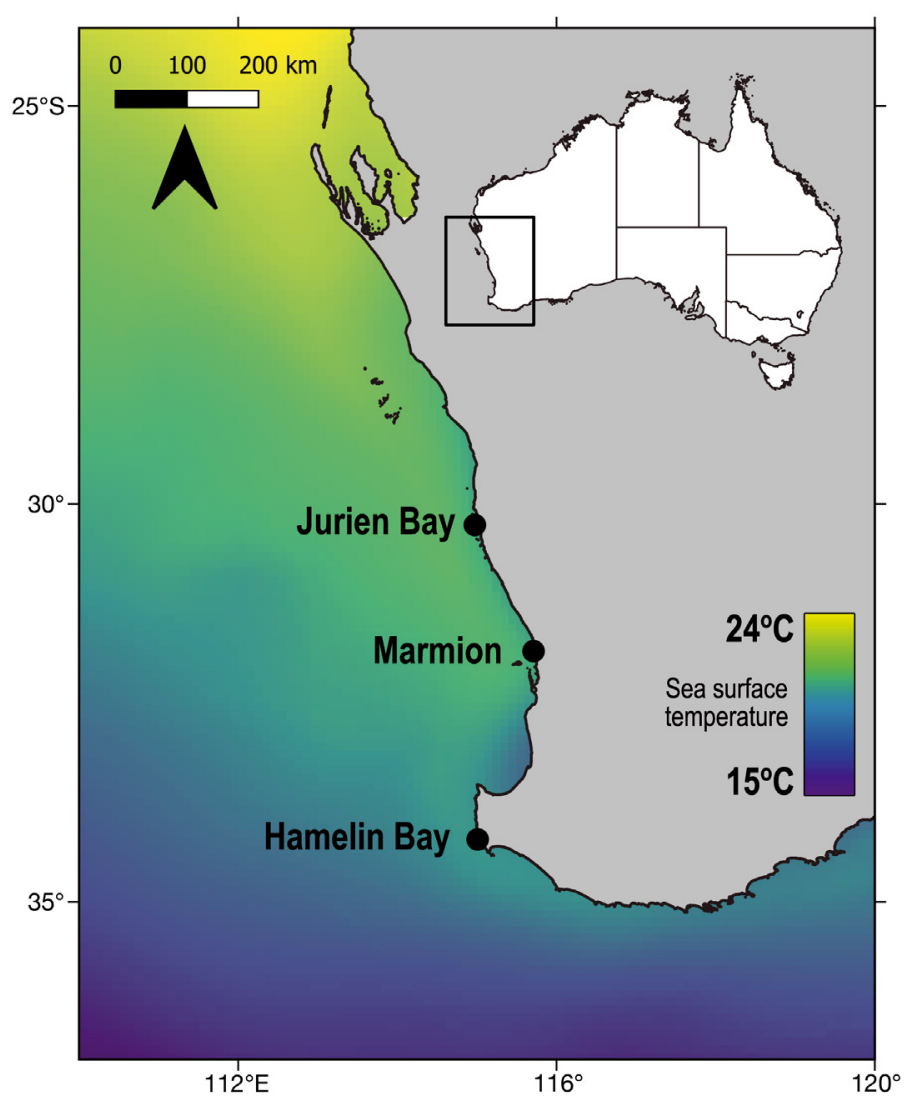

Fig. 1. Survey locations span a latitudinal gradient along the Western Australian coast, with Jurien Bay $\left(30.3^{\circ} \mathrm{S}\right)$ the lowest, Marmion $\left(31.9^{\circ} \mathrm{S}\right)$ in the middle, and Hamelin Bay $\left(34.2^{\circ} \mathrm{S}\right)$ the highest latitude location. Temperature scale indicates mean annual sea surface temperature (SST)

\subsection{Temperature profiles}

Temperature profiles were constructed for each location using sea surface temperature (SST) measured by satellite (IMOS 2019). For each location a mean monthly SST was calculated from January 1993 through to June 2019. A baseline monthly aver- age was calculated by taking the mean SST from each month between January 1993 and December 2010, which was then subtracted from the mean SST for each month from January 2011 to June 2019 to get the SST anomaly for each month. To determine the gradual temperature increase over time, mean summer SST was calculated by taking the mean temperature in March each year. Linear regression was used to calculate the rate of annual SST increase.

\subsection{Sample collection}

Mobile invertebrate abundances were determined at 3-7 sites per location between 2016 and 2019 (for sampling regime details, see Table S1 in the Supplement at www.int-res.com/articles/suppl/m656p227_ supp.pdf). Seasonal variation in sampling time was not included as a factor, as previous studies had found it to be a non-significant contributor to variability of the mobile invertebrate abundances (Vanderklift \& Kendrick 2004). To determine the changes in the invertebrate communities over $15 \mathrm{yr}$, the new surveys were compared to data published by Vanderklift \& Kendrick (2004), which were collected between 1999 and 2001. Using the methods described by Vanderklift \& Kendrick (2004), 12 non-overlapping transects $\left(5 \mathrm{~m}^{2}\right)$ were surveyed at each site by divers on SCUBA. Six transects were placed on reef flat (i.e. where the reef surface is functionally horizontal), and 6 were placed at the base of reef walls (i.e. where the reef surface is roughly vertical). All mobile invertebrates larger than $10 \mathrm{~mm}$ were visually identified to the lowest possible taxonomic level, and counted for abundance. Individuals not identifiable in situ were photographed and identified using additional literature (Atlas of Living Australia 2019).

Separate to the abundance surveys, the size frequency of the conspicuous and most abundant gas- 
tropod, Lunella torquatus, was determined for each location. Between 2006 and 2019, 10 min free roaming searches were performed by divers on SCUBA, and all $L$. torquatus individuals found were collected (See Table S1 for sampling regime details). The size of each individual was subsequently determined by measuring the spire height to the nearest millimeter using Vernier callipers (Wernberg et al. 2008). After measuring, all individuals were returned to the reef. While this data does not go back as far as the abundance data, it does encompass a 13 yr period in which the MHW occurred. Time frames were constructed by pooling all samples from each site in their respective location from before the onset of the MHW (2006-2010; pre-MHW), the anomalously warm period of the MHW and directly after (20112014; MHW), and the subsequent cool period (20152017; post-MHW) (see Fig. 2B). Due to the high mobility of L. torquatus (Ettinger-Epstein \& Kingsford 2008), populations that were sampled at sites which were revisited in subsequent years were assumed to be temporally independent and therefore counted as separate replicates.

\subsection{Statistical analyses}

All statistical tests were done using $R_{3.6 .1}$ ( $R$ Core Team 2019). PCO analysis was performed on the Bray-Curtis dissimilarities of the presence/absence of the invertebrates between transects at each location. The difference between years for each location was determined using PERMANOVA (999 permutations) on the same dissimilarity. For both the PCO and PERMANOVA empty transects were removed. To determine which species contributed most to the dissimilarities between years, a SIMPER analysis was performed over the Bray-Curtis dissimilarities of the log transformed densities of invertebrates of each transect, disregarding location. The PCO, PERMANOVA, and SIMPER analyses were performed using the 'Vegan' package (Oksanen et al. 2010). For comparing mean densities and richness, a nested 2-way factorial linear mixed effects (LME) model with restricted maximum likelihood approach was performed using the 'lme4' package (Bates et al. 2007). In this model Transect was nested within Site, Site was a random effect, and Location (3 levels; Hamelin Bay, Marmion, Jurien Bay) and Year (2 levels; 1999-2001, 2016-2019) were fixed effects. For the LMEs the data was logtransformed, and residuals visually inspected for linearity, normality, and homogeneity of variance.
A post-hoc Tukey HSD test was used to compare individual means. Probability densities of the $L$. torquatus populations were generated using Kernel Density Estimates (KDE) based on the pooled size counts for each location and time frame, using Silverman's rule of thumb (Silverman 1986) to determine the bandwidth. Dissimilarities of the size distributions between time frames were then tested using a 2-sample Kolmogorov-Smirnov (KS) test.

\section{RESULTS}

\subsection{Temperature}

The rate of yearly SST increase (gradual warming) was similar between locations, increasing at a rate of 0.0192, 0.0201, and $0.0242{ }^{\circ} \mathrm{C} \mathrm{yr}^{-1}$ in Jurien Bay, Marmion, and Hamelin Bay, respectively (Table 1; Fig. 2A). While the SST anomaly during the MHW at each location was of comparable magnitude (2$3^{\circ} \mathrm{C}$; Fig. 2B), the higher SSTs at lower latitudes resulted in higher peak temperatures during the MHW (27.97, 26.37, and $24.32^{\circ} \mathrm{C}$ from low to high latitude; Table 1). After the initial MHW, 2 more years of anomalously high SST were seen, after which a cool phase was seen from 2014 onwards, where SST anomalies were generally cooler and less extreme (Fig. 2B).

\subsection{Invertebrate communities}

The mean abundance and richness per transect were lower in 2016-2019 than in 1999-2001 (Table 2, Fig. 3). Additionally, when comparing between locations, the mean abundance and richness in Marmion was higher than in Hamelin Bay or Jurien Bay (Table 2, Fig. 3). Comparing individual means over time, Jurien Bay showed a significant reduction in both density and diversity, in Hamelin Bay only the diversity was lower. The reduction in density or diversity over time in Marmion was minimal (Fig. 3). There was a latitudinal gradient seen in the BrayCurtis dissimilarities over time at each location, with dissimilarities decreasing with increasing latitude. This is seen in the PCO (Fig. 4) and PERMANOVA analyses, where the biggest dissimilarity was found in Jurien Bay (pseudo- $F_{1,68}=8.103, \mathrm{p}<0.001$ ), followed by Marmion (pseudo- $F_{1,348}=7.227, \mathrm{p}<0.001$ ), while in Hamelin Bay the dissimilarity was relatively small (pseudo- $F_{1,68}=1.385, \mathrm{p}=0.218$; see Table S2 in the Supplement). 

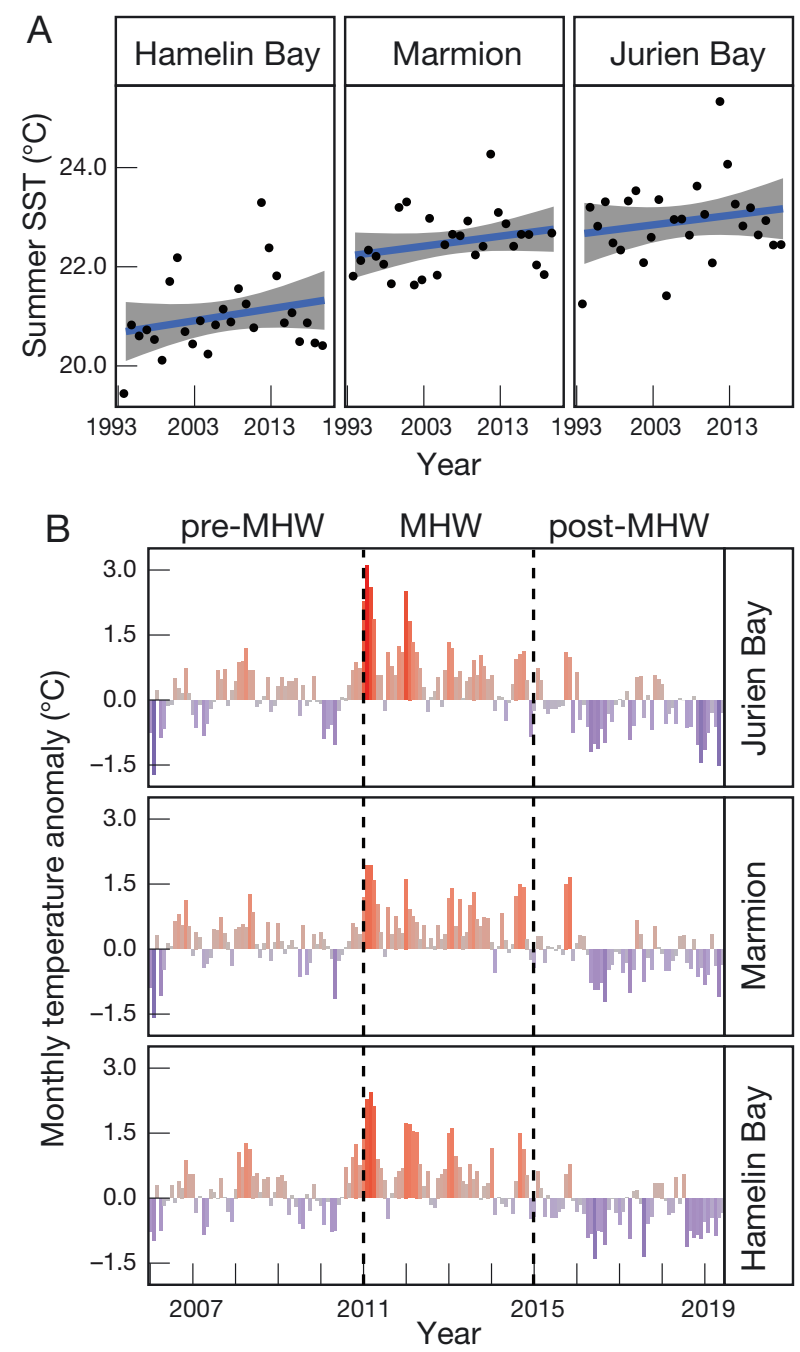

Fig. 2. Long term sea surface temperature (SST) data for each location. (A) Gradual SST increase (blue trend line, grey area indicates $95 \%$ confidence interval; see Table 1 for trend line values) based on mean summer SST temperatures from 1993 to 2019. (B) Monthly SST anomaly from 2010 to 2019 (red bars indicate anomalous warming, blue bars anomalous cooling), referenced against the mean monthly SST from 1992 to 2010. Phases of the Lunella torquatus size distribution analysis are separated by the dashed lines. All SST data was sourced from the Integrated Marine Observing System (IMOS)

\subsection{Individual species abundances}

Over $60 \%$ of the Bray-Curtis dissimilarity between years came from 4 species: urchins Centrostephanus tenuispinus (warm temperate affinity), Heliocidaris erythrogramma (cool temperate), and Phyllacanthus irregularis (cool temperate); and gastropod L. torquatus (cool temperate; see Table S2 for full SIMPER results). These species combined
Table 2. Linear mixed effects (LME) model using restricted maximum likelihood (REML) approach output. Transects were nested in Site, Site was a random effect, Location was a fixed effect (3 levels: Hamelin Bay, Marmion, Jurien Bay), and Year was a fixed effect (2 levels: 1999-2001, 2016-2019). Significant values $(p<0.05)$ in bold

\begin{tabular}{|c|c|c|c|c|c|}
\hline Model & NumDF & DenDF & MS & $F$ & $\operatorname{Pr}(>F)$ \\
\hline \multicolumn{6}{|l|}{ Total abundance } \\
\hline Year & 1 & 22.6 & 4.1173 & 9.7053 & 0.005 \\
\hline Location & 2 & 22.1 & 4.3097 & 10.1589 & 0.001 \\
\hline Year $\times$ Location & 2 & 22.1 & 0.3895 & 0.9182 & 0.414 \\
\hline \multicolumn{6}{|l|}{ Richness } \\
\hline Year & 1 & 23.4 & 2.9069 & 13.9717 & 0.001 \\
\hline Location & 2 & 22.8 & 1.8465 & 8.8751 & 0.001 \\
\hline Year $\times$ Location & 2 & 22.8 & 0.3008 & 1.4460 & 0.256 \\
\hline \multicolumn{6}{|c|}{ Centrostephanus tenuispinus } \\
\hline Year & 1 & 21.4 & 0.3709 & 3.0304 & 0.096 \\
\hline Location & 2 & 21.1 & 0.2828 & 2.3101 & 0.124 \\
\hline Year $\times$ Location & 2 & 21.1 & 0.1847 & 1.5091 & 0.244 \\
\hline \multicolumn{6}{|c|}{ Phyllacanthus irregularis } \\
\hline Year & 1 & 21.3 & 1.0450 & 1.5109 & 0.232 \\
\hline Location & 2 & 21.0 & 1.2913 & 1.8670 & 0.179 \\
\hline Year $\times$ Location & 2 & 21.0 & 0.7248 & 1.0479 & 0.368 \\
\hline \multicolumn{6}{|c|}{ Heliocdaris erythrogramma } \\
\hline Year & 1 & 23.9 & 4.1483 & 3.1244 & 0.090 \\
\hline Location & 2 & 23.4 & 0.7909 & 0.5957 & 0.559 \\
\hline Year $\times$ Location & 2 & 23.4 & 0.1871 & 0.1409 & 0.869 \\
\hline \multicolumn{6}{|l|}{ Lunella torquatus } \\
\hline Year & 1 & 23.8 & 0.1914 & 1.0403 & 0.318 \\
\hline Location & 2 & 23.5 & 0.8504 & 4.6217 & 0.020 \\
\hline Year $\times$ Location & 2 & 23.5 & 0.0006 & 0.0031 & 0.997 \\
\hline
\end{tabular}

accounted for $70.9 \%$ of total abundance counts. There was no significant difference in the mean densities of any of the individual species over time, however L. torquatus was found to have higher densities in Marmion than at the other locations (Table 2, Fig. 5). There was no latitudinal pattern in the densities of either $H$. erythrogramma or $L$. torquatus (Fig. 5). Historically, C. tenuispinus and P. irregularis showed a similar trend of decreasing density towards higher latitudes, however over time $C$. tenuispinus densities increased, while $P$. irregularis decreased. The biggest changes were seen at the lowest latitude (Jurien Bay), where C. tenuispinus showed a mean increase of 0.56 ind. $5 \mathrm{~m}^{-2}$, and $P$. irregularis a decrease of 0.68 ind. $5 \mathrm{~m}^{-2}$. The magnitude of these changes decreased with increasing latitude and little change was seen in the highest latitude (Hamelin Bay) where C. tenuispinus was not recorded in any transect, and $P$. irregularis remained at densities below 0.1 ind. $5 \mathrm{~m}^{-2}$. Furthermore, while $C$. tenuispinus was not found on the reef flats at any location in 1999-2001, in 2016-2019 


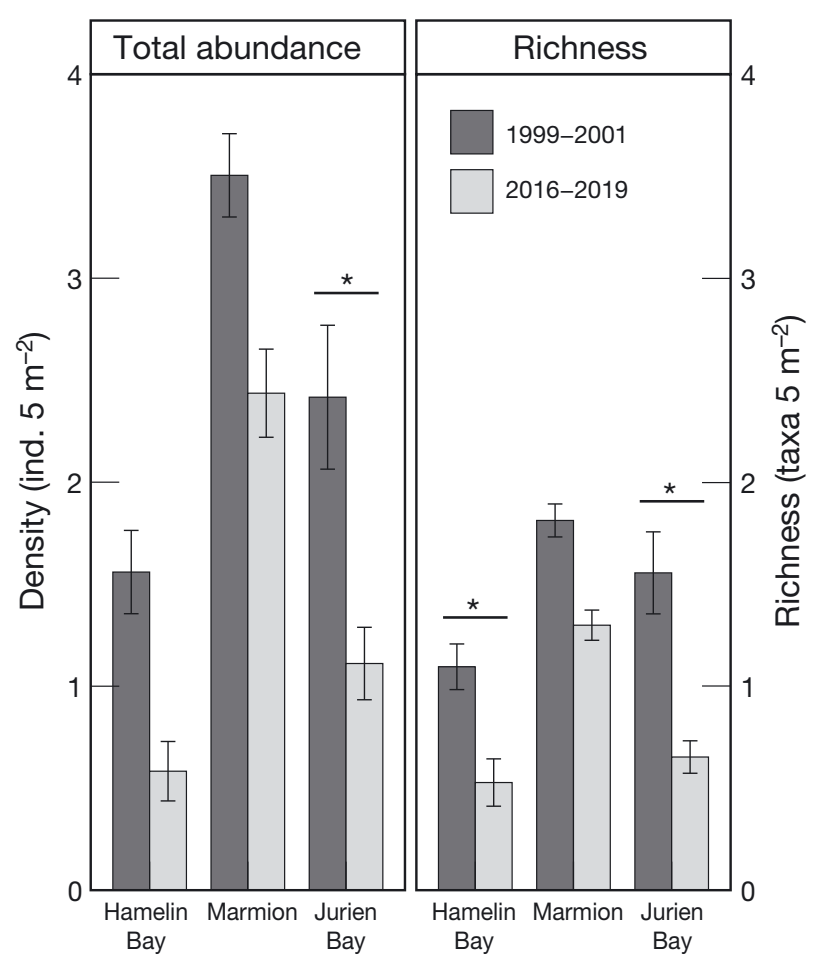

Fig. 3. Density and richness of mobile invertebrates per transect $($ mean \pm SE) at Hamelin Bay $(n=120)$, Marmion $(n=$ $444)$, and Jurien Bay $(\mathrm{n}=108)$ over a 20 yr time interval. Dark bars indicate 1999-2001 census, light bars indicate recent 2016-2019 surveys. Asterisks indicate significant differences between individual means 1999-2001 and 20162019 per location (Tukey HSD, p < 0.05)

over $20 \%$ of C. tenuispinus individuals (11 of 50) were recorded on the reef flat in Jurien Bay, resulting in a mean density of $0.31 \pm 0.17$ ind. $5 \mathrm{~m}^{-2}$ $($ mean $\pm \mathrm{SE})$.

\subsection{Size frequency distribution of Lunella torquatus}

When comparing the size distributions of L. torquatus over the latitudinal gradient (Fig. 6, left column), the peak of size frequency shifted from predominantly small individuals $(\sim 50 \mathrm{~mm})$ at the lowest latitude (Jurien Bay), to predominantly large individuals $(\sim 90 \mathrm{~mm})$ at the highest latitude (Hamelin Bay). In between, Marmion showed 2 peaks ( 40 and $\sim 100 \mathrm{~mm}$ ), with the bigger peak for the smaller sized individuals. While the dissimilarity from Jurien Bay to Marmion to Hamelin was very similar in the period prior to the MHW (KS test: $D=0.40, \mathrm{p}<0.001$ and $D=0.46, \mathrm{p}<0.001$, respectively), the Marmion population in the cool phase following the MHW (Fig. 6, right column) was more similar to the population in Jurien Bay (KS test: $D=0.36, \mathrm{p}=0.190$ ) than it was to Hamelin Bay (KS test: $D=0.75, \mathrm{p}<0.001$ ). However, the efficacy of the KS test was limited by the decrease in abundance of $L$. torquatus in Jurien since the MHW (see also Table S1).

The biggest differences in L. torquatus size distribution over time were seen between the pre-MHW and MHW phases, as well as MHW and the post-MHW phases in Jurien Bay (Fig. 6, first row; KS test: $D=0.63$, $\mathrm{p}=0.008$ and $D=0.65, \mathrm{p}=0.034$ ) and Marmion (Fig. 6, second row; KS test: $D=0.42, \mathrm{p}<0.001$ and $D=0.51$, $\mathrm{p}<0.001$ ). For both Jurien Bay and Marmion smaller individuals dominated the size distribution before the MHW, with the peak frequencies around $50 \mathrm{~mm}$ and $40 \mathrm{~mm}$, respectively. Marmion showed a secondary peak with individuals around $100 \mathrm{~mm}$. In the MHW phase, the number of individuals declined and only
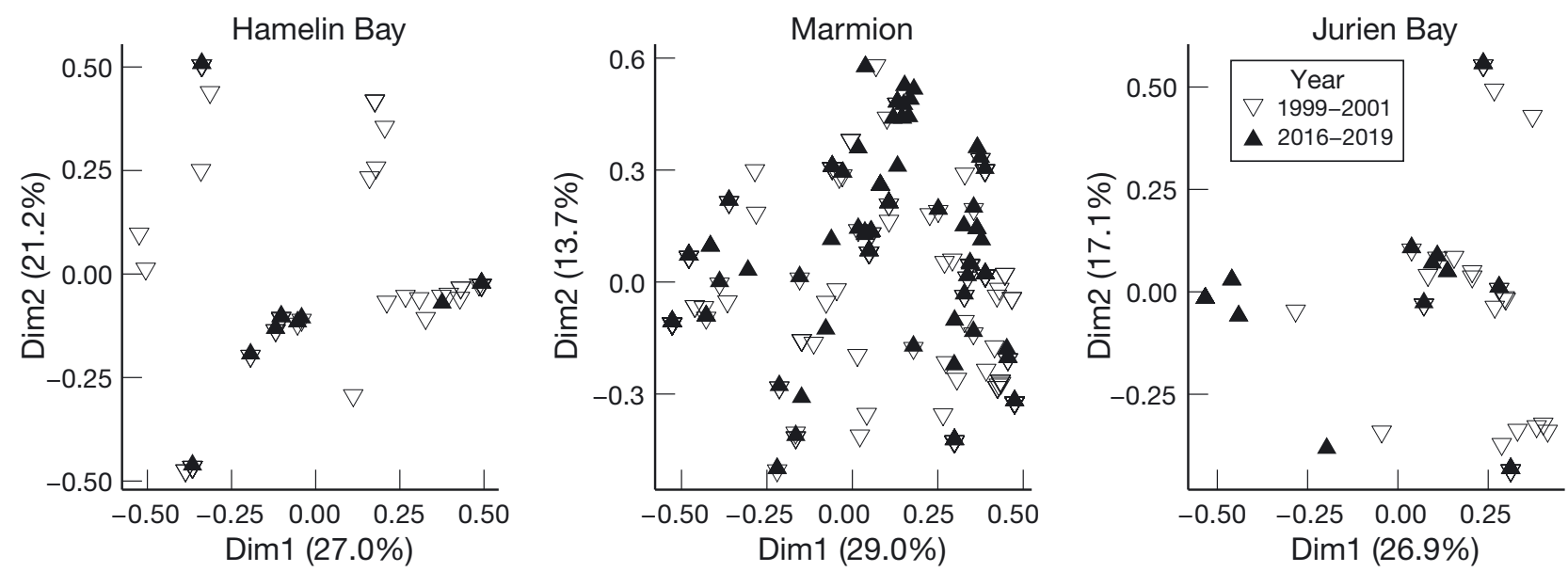

Fig. 4. PCO of the Bray-Curtis dissimilarities of the presence/absence of mobile invertebrates per transect at Hamelin Bay $(\mathrm{n}=$ $70)$, Marmion $(n=350)$, and Jurien Bay $(n=70)$ over a 15 yr time interval. Open triangles indicate 1999-2001 census, closed triangles indicate recent 2016-2019 surveys. See Table S3 in the Supplement for details on PERMANOVA analysis of dissimilarities 


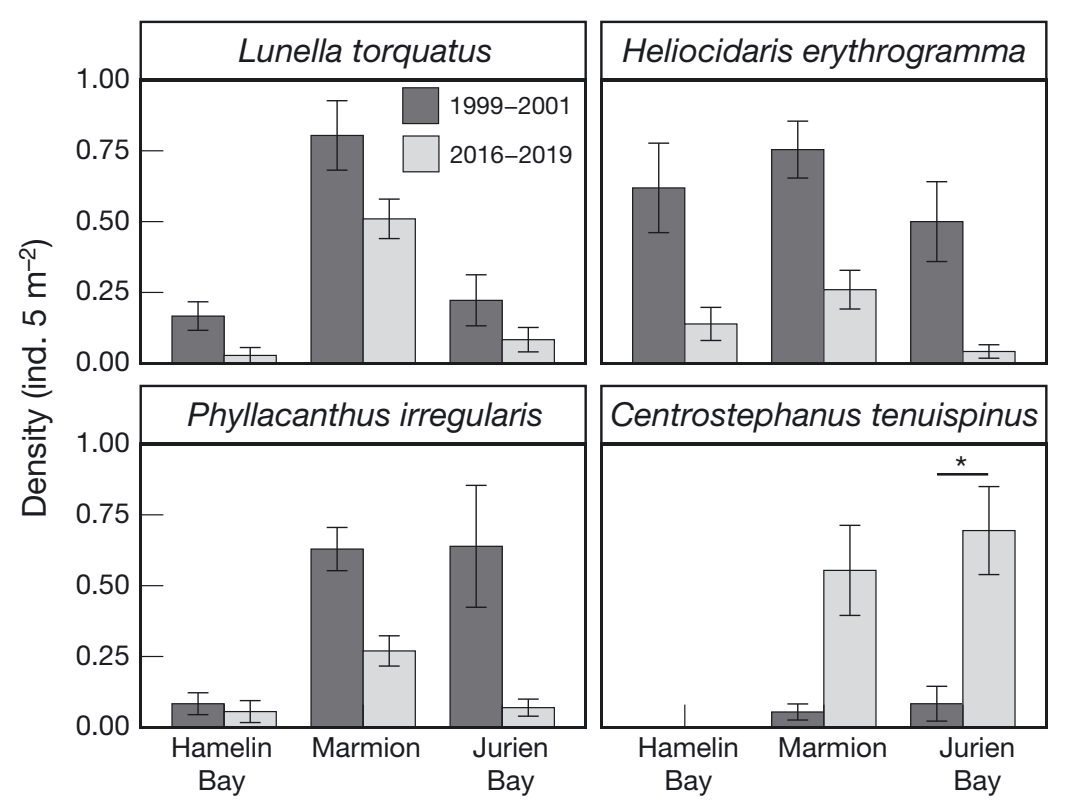

Fig. 5. Densities of the 4 most abundant mobile invertebrates per transect (mean \pm SE) at Hamelin Bay $(n=120)$, Marmion $(n=444)$, and Jurien Bay $(n=108)$ over a 15 yr time interval. Dark bars indicate 1999-2001 census, light bars indicate recent 2016-2019 surveys. Asterisks indicate significant difference between individual means of 1999-2001 and 2016-2019 per location (Tukey HSD, p < 0.05) few were found and measured, with L. torquatus now absent from some sites in Jurien Bay. The defining peaks of small individuals were also lost, resulting in a distribution that was more evenly spread out from the centre. After the MHW, the peaks of small individuals returned to both Jurien Bay and Marmion. Comparing the size distributions before the MHW to after the MHW directly for these locations, there was a smaller difference in the distributions (KS test, $D=0.12, \mathrm{p}=0.999$ and $D=0.16, \mathrm{p}=0.018$, respectively). In Hamelin Bay the size distributions were relatively consistent over time compared to the other locations (Fig. 6, third row). Here, size distributions were dominated by larger individuals, with peak frequencies slightly below $100 \mathrm{~mm}$ size. While there were no significant differences between successive phases $(p=0.356$ and $p=0.104$ for

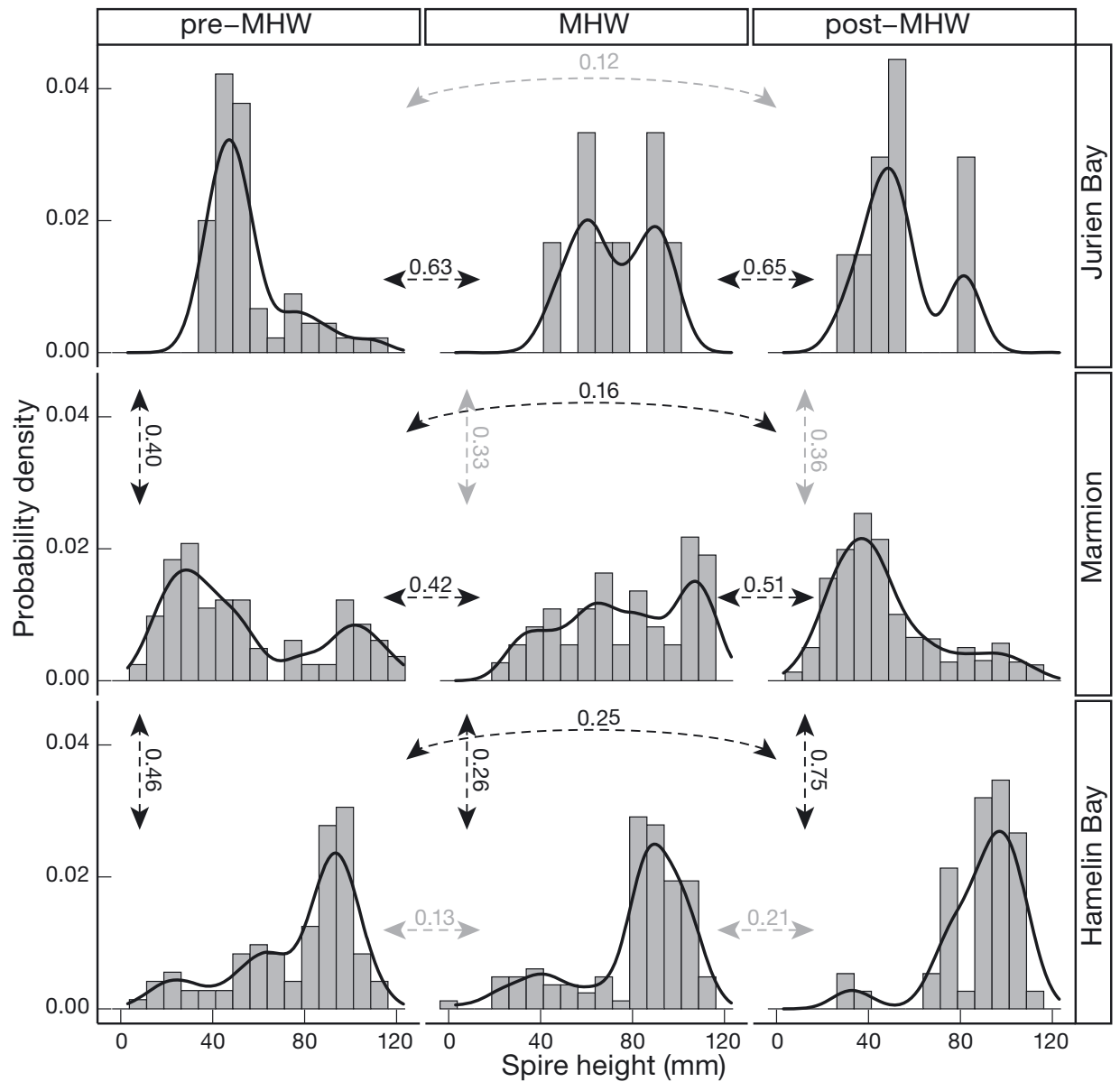

Fig. 6. Size frequencies (bars) and probability densities of size distribution (black line) of Lunella torquatus individuals based on Kernel Density Estimates (KDE) found at Jurien Bay ( $\mathrm{n}=77$ ), Marmion ( $\mathrm{n}=768$ ), and Hamelin Bay $(\mathrm{n}=256)$ divided into 3 time phases; pre-MHW (2006-2010) in the left column, MHW (20112014) in the middle, and post-MHW (2015-2017) on the right. Bandwidth of each KDE was $7.48 \mathrm{~mm}$ calculated using Silverman's rule of thumb. Kolmogorov-Smirnov $D$-values are given to indicate dissimilarity between size distributions connected with dashed arrow line, with significant values $(p<0.05)$ in black, while non-significant values $(p \geq 0.05)$ are in grey 
pre-MHW to MHW to post-MHW, respectively), there was a significant difference from before the MHW to after the MHW (KS test: $D=0.25, \mathrm{p}=0.029$ ). After the MHW, the most frequent size class was slightly larger than before, and smaller individuals are nearly absent.

\section{DISCUSSION}

The north-south orientation of the WA coastline makes it a tremendous area to study the effect of temperature on an ecosystem, as the latitudinal gradient serves as a proxy for cumulative heat stress of combined gradual warming and impact of a recent acute heat event. Although there are inherent confounding effects from environmental parameters such as light, nutrients, and wave exposure that could influence the mobile invertebrate communities at the site level, temperature is likely the main driver between locations as it varies most consistently over latitude (Wernberg et al. 2010). We found the biggest changes to the mobile invertebrate community at the lowest latitude, whereas changes at middle and high latitudes were less pronounced. There was a latitudinal pattern in the increase of Centrostephanus tenuispinus (warmtemperate affinity), and in the decrease of Phyllacanthus irregularis (cool-temperate affinity) densities, where the magnitude of change decreased with increasing latitude. The size frequency distribution of cool-temperate Lunella torquatus reflected the impact of the MHW; however, the recovery seen in the size distribution was not seen in the total abundances.

\subsection{Thermal stress gradient}

As the coastline investigated forms a transition zone between the temperate Flindersian and the tropical Damperian region (Huisman et al. 1998, Wernberg et al. 2013b), low latitude temperate populations are at the warm edge of their distribution and thus vulnerable to temperature stress (Sunday et al. 2012, Wernberg et al. 2013a). The gradual warming identified here was in the same order of magnitude at all locations. Despite high inter-annual variability (i.e. low $\mathrm{r}^{2}$ values of the correlation of mean SST over time; Table 1), the annual increases in SST at each location were comparable to that reported for the region more broadly (Pearce \& Feng 2007). The SST anomalies recorded during the
MHW were also similar at all locations, but the higher mean absolute temperatures at the lower latitudes resulted in higher peak SSTs. As such, the gradient in peak temperatures likely influenced the gradient of impact of the MHW (Wernberg et al. 2013a, 2016a, 2018). Combining both gradual increases and MHW impact, we can use the latitudinal gradient as a proxy for temperature stress each location experienced over the past 2 decades; high in the lowest latitude (Jurien Bay), medium in the middle latitude (Marmion), and low in the high latitude (Hamelin Bay) location.

The impact of the MHW on mobile invertebrates is clearly shown in the size distributions of L. torquatus, and corresponds with the reduction of absolute abundance reported directly following the MHW (Smale et al. 2017). However, while the size distributions returned to pre-MHW patterns, the absolute abundance remained reduced for all species except the warm temperate urchin $C$. tenuispinus. This suggests that aside from direct lethal effects through heat stress and hypoxia (Pearce \& Feng 2013), there are additional indirect pathways through which temperature stress could have affected the mobile invertebrate communities on WA's temperate reefs, which persist after multiple years of cooler SSTs. One of the biggest effects of the marine heatwave was the reduction in the density and cover of canopy-forming macroalgae (Smale \& Wernberg 2013, Wernberg et al. 2013a), which has shown little to no recovery (Wernberg et al. 2016a, Wernberg 2020). The concept of the loss of a foundation species leading to the loss of the diversity and abundance of dependent species is well established (Ellison et al. 2005, HoeghGuldberg \& Bruno 2010, Thomson et al. 2015). This is what was recorded just after the MHW in WA, where the complete loss of canopy in Kalbarri coincided with the decimation of the mobile invertebrates that were living there (Smale et al. 2017). Furthermore, there has been a clear link established between $L$. torquatus and the need of canopy as shelter (Ettinger-Epstein \& Kingsford 2008). The reduction in available habitat could be reducing the carrying capacity for the species that depend on them, resulting in lower absolute abundances.

Moreover, even for most invertebrates that do not depend on macroalgal canopy for habitat, a reduction in abundance was recorded (e.g. H. erythrogramma, $P$. irregularis). As the main benthic primary producers on temperate reefs, macroalgae provide a significant amount of energy production to the ecosystem, in the form of standing biomass consumed by herbivores (Vanderklift et al. 2006, Crawley \& Hyn- 
des 2007), exuded carbon for bacteria and filter feeders (Wada et al. 2007, Rix et al. 2017), and detritus as the macroalgae senesce and erode (De Bettignies et al. 2013). As the abundance of previously dominant E. radiata is reduced in favour of Sargassum species or turf algae (Wernberg et al. 2016b, Filbee-Dexter \& Wernberg 2018), there could be a reduction of primary production which would limit the resources needed to maintain the total abundance of mobile invertebrates recorded pre-MHW. Furthermore, with the increase in abundance of $C$. tenuispinus there might be more competition, resulting in the decrease in $P$. irregularis in particular, since it shares a similar diet to C. tenuispinus (Vanderklift et al. 2006).

\subsection{Increase in Centrostephanus tenuispinus abundance}

The only species which showed significant increase in abundance was $C$. tenuispinus. While there are no reports of urchin barrens being present on Western Australian temperate reefs, localized high densities of $C$. tenuispinus $\left(5.0 \pm 0.8\right.$ ind. $\mathrm{m}^{-2}$ ) on Hall Bank, Marmion Lagoon co-occurs with the highest percent cover of high latitude corals in the world (Thomson \& Frisch 2010). It has been suggested that the high herbivory rate of $C$. tenuispinus is the main mechanism for subduing the otherwise dominant macroalgal canopy, in favour of the corals (Thomson \& Frisch 2010). There is indeed strong evidence of the importance of herbivory for the long term success of corals in other systems (Hughes et al. 2007). While the abundances of $C$. tenuispinus have increased in both Marmion and Jurien Bay, with the highest densities found on reef walls in Jurien Bay ( 0.23 ind. $\mathrm{m}^{-2}$ ), these are still an order of magnitude lower compared to densities found on barrens elsewhere in Australia. The congener $C$. rodgersii has been reported at densities of $\sim 3$ ind. $\mathrm{m}^{-2}$ in NSW (Andrew \& Underwood 1989) and $\sim 2$ ind. $\mathrm{m}^{-2}$ in Tasmania (Ling \& Johnson 2009). Furthermore, the densities needed to change the canopy dominated state to barren is suggested to be several times higher than the densities needed to maintain barrens (Hill et al. 2003).

An investigation into the diet of $C$. tenuispinus on temperate reefs showed an abundance of animal tissues in the stomach content, as well as an elevated $\delta^{15} \mathrm{~N}$ compared to that of the dominant macroalgae, Ecklonia radiata (Vanderklift et al. 2006). This suggests that $C$. tenuispinus is not predominantly feeding on macroalgae, but more on sponges and ascidians. This could be the result of selective feeding on sources with high nitrogen, and selective feeding has been reported for C. rodgersii (Wright et al. 1997). Due to the habitat partitioning where $C$. tenuispinus is predominantly found on the reef walls combined with strong site fidelity, the grazing by $C$. tenuispinus would be focussed mostly on the areas dominated by sessile filter feeders, such as the sponges and ascidians found abundantly in the gut content. As such, opportunistic feeding should not be ruled out as a possible explanation for the $C$. tenuispinus dietary preference. It is therefore alarming to see the increase in C. tenuispinus abundances on the reef flats in Jurien Bay, where they could contribute to an ongoing reduction or collapse of macroalgal canopies in the near future.

\subsection{Size structure of $L$. torquatus populations}

The magnitude of the difference in the size structure of the L. torquatus populations reflected the impact gradient of the MHW. At the highest latitude location (Hamelin Bay), where despite increased temperatures the MHW impact was negligible (Smale \& Wernberg 2013, Wernberg et al. 2013a, 2018), the changes to the size structure of the population was not significant. At lower latitudes, where significant changes were seen at both Marmion and Jurien Bay, the frequency peak for smaller individuals disappeared suggesting an impact on recruitment or young individuals. Multiple factors could have contributed to this reduction: direct lethal effects from passing a thermal threshold (Pörtner 2001, Sokolova et al. 2012), susceptibility to predation (e.g. shelter loss (Ettinger-Epstein \& Kingsford 2008), loss of foot strength (Leung et al. 2017), loss of coordinated locomotion (Diaz et al. 2011, Vinagre et al. 2015)), and/or energy reserve depletion (Leung et al. 2017). The decimation at multiple sites in Jurien Bay suggests that the thermal threshold here was surpassed, but the slightly lower temperatures in Marmion may have shifted the main contributing factors to favour survival in larger individuals, which became relatively more abundant. A similar pattern was found for Turbo intercostalis - a relative of $L$. torquatus - at Point Quobba, WA ( $\left.24^{\circ} 29^{\prime} \mathrm{S}, 113^{\circ} 24^{\prime} \mathrm{E}\right)$, after a catastrophic event (Joll 1980).

After the MHW, L. torquatus remained absent at sites in Jurien Bay where populations were found before the MHW, although increase in frequency of smaller individuals at one of the surveyed sites indicates that there is still some level of recruitment. Similarly at Marmion there was a recruitment of smaller 
individuals, while there was a relative decrease of larger individuals. This decrease could be attributed to the cohort of larger individuals naturally expiring without being replaced by the next cohort, which was heavily impacted by the heatwave. The recovery here, however, was seen at all sites and the size structure of the population was more similar to that before the MHW. Likely aiding the recovery are high historical abundances (Vanderklift \& Kendrick 2004, Wernberg et al. 2008) and more potential for planktonic larvae to be brought down by the Leeuwin Current (Caputi et al. 1996, Pearce et al. 2011b), as it is further south of the northern edge of the distribution range, which would supplement asynchronous spawning events (Joll 1980, Ward \& Davis 2002). Despite the recovery of the size structure of the population, total abundances remain lower than before the MHW. Considering that the reduction in canopy cover persists to this day (Wernberg et al. 2016a, Wernberg 2020 ), it is possible that this reduction in the available habitat for the species on the reef flats to exploit lowers the carrying capacity for mobile invertebrates of the reef.

\subsection{Conclusions}

The latitudinal gradient along the WA coast can serve as a proxy for cumulative heat stress over the last decades, with lower latitudes under higher stress than higher latitudes. While more factors (e.g. habitat loss, resource competition) could influence absolute abundances, warm temperate urchin C. tenuispinus increased, while cool temperate urchin $P$. irregularis decreased in abundance relative to this heat stress gradient. At the lowest latitude location, the C. tenuispinus population has expanded onto the reef flats, where before it was restricted to the reef walls. Although this makes the macroalgae here susceptible to grazing, densities have not yet approached those reported for urchin barrens elsewhere. While cool temperate gastropod $L$. torquatus did not show a trend in absolute densities over the latitudinal gradient, there was a change in size-frequency distribution relative to the impact of the MHW, which did recover. The trend in size distribution over latitude however, does show a reduction in frequency of larger individuals at lower latitude. As sea temperatures are projected to continue to increase, so will the thermal stress on the temperate ecosystems. Populations at the warm edge of their distribution are showing larger changes, a response which over time can be expected to increase in magnitude, and also start occurring in higher latitudes.
Acknowledgements. Thanks to Matt Vanderklift for collecting and letting us use the original dataset, as well as insightful knowledge on the biology and ecology of mobile invertebrates in Western Australia. Further thanks to Karen Filbee-Dexter for comments on the manuscript, and countless members of the Wernberg laboratory, past and present, who assisted with fieldwork and data collection. All SST data were sourced from the Integrated Marine Observing System (IMOS); IMOS is a national collaborative research infrastructure, supported by the Australian Government. Funding for this research was received from Holsworth Wildlife Research Endowment, and an Australian Government Research Training Program (RTP) Scholarship to Y.R.M., and the Australian Research Council (DP0555929, DP170100023 and DP190100058) to T.W.

\section{LITERATURE CITED}

Andrew NL, O'Neill AL (2000) Large-scale patterns in habitat structure on subtidal rocky reefs in New South Wales. Mar Freshw Res 51:255-263

Andrew NL, Underwood AJ (1989) Patterns of abundance of the sea urchin Centrostephanus rodgersii (Agassiz) on the central coast of New South Wales, Australia. J Exp Mar Biol Ecol 131:61-80

* Andrew NL, Underwood AJ (1993) Density-dependent foraging in the sea urchin Centrostephanus rodgersii on shallow subtidal reefs in New South Wales, Australia. Mar Ecol Prog Ser 99:89-89

Atlas of Living Australia (2019) Atlas of living Australia. https://www.ala.org.au (accessed January 1, 2019)

Bates D, Sarkar D, Bates MD, Matrix L (2007) The lme4 package. R package version 2. http://CRAN.R-project. org/package $=$ lme 4

*Bennett S, Wernberg T, Harvey ES, Santana-Garcon J, Saunders BJ (2015) Tropical herbivores provide resilience to a climate-mediated phase shift on temperate reefs. Ecol Lett 18:714-723

* Bennett S, Wernberg T, Connell SD, Hobday AJ, Johnson CR, Poloczanska ES (2016) The 'Great Southern Reef': social, ecological and economic value of Australia's neglected kelp forests. Mar Freshw Res 67:47-56

Bowler DE, Hof C, Haase P, Kröncke I and others (2017) Cross-realm assessment of climate change impacts on species' abundance trends. Nat Ecol Evol 1:67

Caputi N, Fletcher WJ, Pearce A, Chubb CF (1996) Effect of the Leeuwin Current on the recruitment of fish and invertebrates along the Western Australian coast. Mar Freshw Res 47:147-155

Caputi N, Feng M, Pearce A, Benthuysen J and others (2015) Management implications of climate change effect on fisheries in Western Australia Part 1: Environmental change and risk assessment. FRDC Project 2010/ 535. Fisheries Research Report No. 260, Department of Fisheries, Western Australia

Coleman MA, Wernberg T (2017) Forgotten underwater forests: the key role of fucoids on Australian temperate reefs. Ecol Evol 7:8406-8418

Crawley KR, Hyndes GA (2007) The role of different types of detached macrophytes in the food and habitat choice of a surf-zone inhabiting amphipod. Mar Biol 151:1433-1443

De Bettignies T, Wernberg T, Lavery PS, Vanderklift MA, Mohring MB (2013) Contrasting mechanisms of dis- 
lodgement and erosion contribute to production of kelp detritus. Limnol Oceanogr 58:1680-1688

Diaz F, Salas A, Re AD, Gonzalez M, Reyes I (2011) Thermal preference and tolerance of Megastrea (Lithopoma) undosa (Wood, 1828; Gastropoda: Turbinidae). J Therm Biol 36:34-37

Ellison A, Bank M, Clinton B, Colburn E and others (2005) Loss of foundation species: consequences for the structure and dynamics of forested ecosystems. Front Ecol Environ 3:479-486

Ettinger-Epstein P, Kingsford MJ (2008) Effects of the El Niño southern oscillation on Turbo torquatus (Gastropoda) and their kelp habitat. Austral Ecol 33:594-606

Filbee-Dexter K, Scheibling RE (2014) Sea urchin barrens as alternative stable states of collapsed kelp ecosystems. Mar Ecol Prog Ser 495:1-25

Filbee-Dexter K, Wernberg T (2018) Rise of turfs: a new battlefront for globally declining kelp forests. Bioscience 68 : $64-76$

Hill NA, Blount C, Poore AGB, Worthington D, Steinberg PD (2003) Grazing effects of the sea urchin Centrostephanus rodgersii in two contrasting rocky reef habitats: effects of urchin density and its implications for the fishery. Mar Freshw Res 54:691-700

Hobday AJ, Pecl GT (2014) Identification of global marine hotspots: sentinels for change and vanguards for adaptation action. Rev Fish Biol Fish 24:415-425

Hobday AJ, Alexander LV, Perkins SE, Smale DA and others (2016) A hierarchical approach to defining marine heatwaves. Prog Oceanogr 141:227-238

Hoegh-Guldberg O, Bruno JF (2010) The impact of climate change on the world's marine ecosystems. Science 328: 1523-1528

Hughes TP, Rodrigues MJ, Bellwood DR, Ceccarelli D and others B (2007) Phase shifts, herbivory, and the resilience of coral reefs to climate change. Curr Biol 17:360-365

* Huisman JM, Cowan RA, Entwisle TJ (1998) Biodiversity of Australian marine macroalgae-a progress report. Bot Mar 41:89-94

IMOS (Integrated Marine Observing System) (2019) IMOS SRS - SST - L3S - Single Sensor - 6 day - day and night time Australia. http://imos.aodn.org.au (accessed June 6, 2019)

IPCC (Intergovernmental Panel on Climate Change) (2018) Global Warming of $1.5^{\circ} \mathrm{C}$ : an IPCC special report on the impacts of global warming of $1.5^{\circ} \mathrm{C}$ above pre-industrial levels and related global greenhouse gas emission pathways, in the context of strengthening the global response to the threat of climate change, sustainable development, and efforts to eradicate poverty. In: Masson-Delmotte V, Zhai P, Pörtner HO, Roberts D and others (eds) Intergovernmental Panel on Climate Change, Geneva

Johnson C, Ling S, Ross D, Shepherd S, Miller K (2005) Establishment of the long-spined sea urchin (Centrostephanus rodgersii) in Tasmania: first assessment of potential threats to fisheries. FRDC Project 2001/044. School of Zoology and Tasmanian Aquaculture and Fisheries Institute, Hobart

Johnson CR, Banks SC, Barrett NS, Cazassus F and others (2011) Climate change cascades: shifts in oceanography, species' ranges and subtidal marine community dynamics in eastern Tasmania. J Exp Mar Biol Ecol 400:17-32

Joll LM (1980) Reproductive biology of two species of Turbinidae (Mollusca: Gastropoda). Aust J Mar Freshw Res 31:319-336

Kerswell AP (2006) Global biodiversity patterns of benthic marine algae. Ecology 87:2479-2488

*Leung JYS, Connell SD, Russell BD (2017) Heatwaves diminish the survival of a subtidal gastropod through reduction in energy budget and depletion of energy reserves. Sci Rep 7:17688

Ling SD (2008) Range expansion of a habitat-modifying species leads to loss of taxonomic diversity: a new and impoverished reef state. Oecologia 156:883-894

* Ling SD, Johnson CR (2009) Population dynamics of an ecologically important range-extender: kelp beds versus sea urchin barrens. Mar Ecol Prog Ser 374:113-125

* Ling SD, Johnson CR (2012) Marine reserves reduce risk of climate-driven phase shift by reinstating size- and habitatspecific trophic interactions. Ecol Appl 22:1232-1245

* Ling SD, Johnson CR, Frusher S, King CK (2008) Reproductive potential of a marine ecosystem engineer at the edge of a newly expanded range. Glob Change Biol 14: 907-915

King SD, Scheibling RE, Rassweiler A, Johnson CR and others (2015) Global regime shift dynamics of catastrophic sea urchin overgrazing. Philos Trans R Soc Lond B Biol Sci 370:20130269

* Oksanen J, Blanchet FG, Kindt R, Legendre P and others (2010) Vegan: community ecology package. R package version 1. http://CRAN.R-project.org/package=vegan

* Oliver ECJ, Donat MG, Burrows MT, Moore PJ and others (2018) Longer and more frequent marine heatwaves over the past century. Nat Commun 9:1324

O Oliver ECJ, Burrows MT, Donat MG, Sen Gupta A and others (2019) Projected marine heatwaves in the 21st century and the potential for ecological impact. Front Mar Sci 6:734

*Pearce A, Feng M (2007) Observations of warming on the Western Australian continental shelf. Mar Freshw Res 58:914-920

* Pearce AF, Feng M (2013) The rise and fall of the 'marine heat wave' off Western Australia during the summer of 2010/2011. J Mar Syst 111-112:139-156

Pearce A, Lenanton R, Jackson G, Moore J, Feng M, Gaughan D (2011a) The 'marine heat wave' off Western Australia during the summer of 2010/11. FRDC Project 2010/11. Fisheries Research Report No. 222, Department of Fisheries, Western Australia

* Pearce A, Slawinski D, Feng M, Hutchins B, Fearns P (2011b) Modelling the potential transport of tropical fish larvae in the Leeuwin Current. Cont Shelf Res 31:2018-2040

* Perry AL, Low PJ, Ellis JR, Reynolds JD (2005) Climate change and distribution shifts in marine fishes. Science 308:1912-1915

* Poloczanska ES, Brown CJ, Sydeman WJ, Kiessling W and others (2013) Global imprint of climate change on marine life. Nat Clim Change 3:919-925

*Poloczanska ES, Burrows MT, Brown CJ, García Molinos J and others (2016) Responses of marine organisms to climate change across oceans. Front Mar Sci 3:62

* Pörtner HO (2001) Climate change and temperature-dependent biogeography: oxygen limitation of thermal tolerance in animals. Naturwissenschaften 88:137-146

R Core Team (2019) R: a language and environment for statistical computing. R Foundation for Statistical Computing, Vienna. https://www.r-project.org

Rix L, de Goeij JM, van Oevelen D, Struck U, Al-Horani FA, Wild C, Naumann MS (2017) Differential recycling of coral and algal dissolved organic matter via the sponge loop. Func Ecol 31:778-789 
Schiel DR, Steinbeck JR, Foster MS (2004) Ten years of induced ocean warming causes comprehensive changes in marine benthic communities. Ecology 85:1833-1839

Sheridan JA, Bickford D (2011) Shrinking body size as an ecological response to climate change. Nat Clim Change 1:401-406

Silverman BW (1986) Density estimation for statistics and data analysis. Monographs on Statistics and Applied Probability. Chapman \& Hall, London

Smale DA, Wernberg T (2013) Extreme climatic event drives range contraction of a habitat-forming species. Proc $\mathrm{R}$ Soc B 280:20122829

Smale DA, Wernberg T, Vanderklift MA (2017) Regionalscale variability in the response of benthic macroinvertebrate assemblages to a marine heatwave. Mar Ecol Prog Ser 568:17-30

Sokolova IM, Frederich M, Bagwe R, Lannig G, Sukhotin AA (2012) Energy homeostasis as an integrative tool for assessing limits of environmental stress tolerance in aquatic invertebrates. Mar Environ Res 79:1-15

Steneck RS, Graham MH, Bourque BJ, Corbett D, Erlandson JM, Estes JA, Tegner MJ (2002) Kelp forest ecosystems: biodiversity, stability, resilience and future. Environ Conserv 29:436-459

Straub SC, Wernberg T, Thomsen MS, Moore PJ, Burrows M, Harvey BP, Smale DA (2019) Resistance to obliteration; responses of seaweeds to marine heatwaves. Front Mar Sci 6:763

Sunday JM, Bates AE, Dulvy NK (2012) Thermal tolerance and the global redistribution of animals. Nat Clim Change 2:686-690

Thomsen MS, Mondardini L, Alestra T, Gerrity S and others (2019) Local extinction of bull kelp (Durvillaea spp.) due to a marine heatwave. Front Mar Sci 6:84

* Thomson DP, Frisch AJ (2010) Extraordinarily high coral cover on a nearshore, high-latitude reef in south-west Australia. Coral Reefs 29:923-927

Thomson JA, Burkholder DA, Heithaus MR, Fourqurean JW, Fraser MW, Statton J, Kendrick GA (2015) Extreme temperatures, foundation species, and abrupt ecosystem change: an example from an iconic seagrass ecosystem. Glob Change Biol 21:1463-1474

Tuckett CA, de Bettignies T, Fromont J, Wernberg $\mathrm{T}$ (2017) Expansion of corals on temperate reefs: direct and indirect effects of marine heatwaves. Coral Reefs 36:947-956

Vanderklift MA, Kendrick GA (2004) Variation in abundances of herbivorous invertebrates in temperate subtidal rocky reef habitats. Mar Freshw Res 55:93-103

Vanderklift MA, Kendrick GA, Smit AJ (2006) Differences in

Editorial responsibility: Laura Falkenberg (Guest Editor), Hong Kong, SAR

Reviewed by: 3 anonymous referees trophic position among sympatric sea urchin species. Estuar Coast Shelf Sci 66:291-297

* Vinagre C, Leal I, Mendonça V, Flores AAV (2015) Effect of warming rate on the critical thermal maxima of crabs, shrimp and fish. J Therm Biol 47:19-25

Wada S, Aoki MN, Tsuchiya Y, Sato T, Shinagawa H, Hama $\mathrm{T}$ (2007) Quantitative and qualitative analyses of dissolved organic matter released from Ecklonia cava Kjellman, in Oura Bay, Shimoda, Izu Peninsula, Japan. J Exp Mar Biol Ecol 349:344-358

Ward DW, Davis AR (2002) Reproduction of the turban shell Turbo torquatus Gmelin 1791 (Mollusca: Gastropoda), in New South Wales, Australia. Mar Freshw Res 53:85-91

Wernberg T (2020) Marine heatwave drives collapse of kelp forests in Western Australia. In: Canadell JG, Jackson RB (eds) Ecosystem collapse and climate change. SpringerNature (in press)

Wernberg T, White M, Vanderklift MA (2008) Population structure of turbinid gastropods on wave-exposed subtidal reefs: effects of density, body size and algae on grazing behaviour. Mar Ecol Prog Ser 362:169-179

* Wernberg T, Thomsen MS, Tuya F, Kendrick GA, Staehr PA, Toohey BD (2010) Decreasing resilience of kelp beds along a latitudinal temperature gradient: potential implications for a warmer future. Ecol Lett 13:685-694

Wernberg $T$, Smale D, Tuya F, Thomsen $M$ and others (2013a) An extreme climatic event alters marine ecosystem structure in a global biodiversity hotspot. Nat Clim Change 3:78-82

*Wernberg T, Thomsen MS, Connell SD, Russell BD and others (2013b) The footprint of continental-scale ocean currents on the biogeography of seaweeds. PLOS ONE 8: e80168

*Wernberg T, Bennett S, Babcock RC, de Bettignies T and others (2016a) Climate-driven regime shift of a temperate marine ecosystem. Science 353:169-172

* Wernberg T, de Bettignies T, Joy BA Finnegan PM (2016b) Physiological responses of habitat-forming seaweeds to increasing temperatures. Limnol Oceanogr 61:2180-2190

* Wernberg T, Coleman MA, Bennett S, Thomsen MS, Tuya F, Kelaher BP (2018) Genetic diversity and kelp forest vulnerability to climatic stress. Sci Rep 8:1851

WWernberg T, Coleman MA, Babcock RC, Bell SY and others (2019) Biology and ecology of the globally significant kelp Ecklonia radiata. Oceanogr Mar Biol Annu Rev 57: 265-324

Wright JT, Benkendorff K, Davis AR (1997) Habitat associated differences in temperate sponge assemblages: the importance of chemical defence. J Exp Mar Biol Ecol 213:199-213

Submitted: January 14, 2020

Accepted: November 4, 2020

Proofs received from author(s): December 7, 2020 